\title{
Alcohol: Keep it moderate
}

\author{
Nicholas Gerard Smedira, MD, MBA
}

\author{
From the Department of Thoracic and Cardiovascular Surgery, Cleveland Clinic, Heart and Vascular Institute, \\ Cleveland, Ohio. \\ Disclosures: Author has nothing to disclose with regard to commercial support. \\ Received for publication Oct 11, 2018; accepted for publication Oct 12, 2018. \\ Address for reprints: Nicholas Gerard Smedira, MD, MBA, Cleveland Clinic, 9500 Euclid Ave, Cleveland, OH \\ 44195 (E-mail: smedirn@ccf.org). \\ J Thorac Cardiovasc Surg 2019;157:304-5 \\ $0022-5223 / \$ 36.00$ \\ Copyright (c) 2018 by The American Association for Thoracic Surgery \\ https://doi.org/10.1016/j.jtcvs.2018.10.054
}

If you do a Google search about guidelines for alcohol use, you will find a recommendation from the Mayo Clinic that states, "Moderate alcohol use has possible health benefits, but it's not risk free." 1 This is in reference to imbibing alcohol. What about injecting alcohol into a septal artery? As we contemplate the very well-written article in this issue of the Journal by Nguyen and colleagues, ${ }^{2}$ another welldesigned study from this storied medical center and world-renowned cardiology and cardiac surgical team, I will approach it from the patient's perspective.

The Mayo Clinic team has set the quality standards to which every center treating patients with hypertrophic obstructive cardiomyopathy must strive for. They report no in-hospital deaths after either septal myectomy or alcohol septal ablation (ASA) and low rates of nonfatal complications in both groups. Moving from the center's perspective to that of the patient, we can address some commonly asked questions about the procedures.

One commonly asked question is "Will I need a pacemaker?" It is uncommon after a myectomy, and 4 to 5 times more frequent with septal ablation. The actual percentage after ASA is $17.4 \%$. Some percentage of the patients who need a pacemaker will also need an implantable cardioverter defibrillator for primary prevention, so the actual avoidance of an implantable cardioverter defibrillator or pacemaker is likely less-at least from the patient's perspective-but it is definitely more common after ASA.

Reintervention rates, as in many surgical versus percutaneous comparisons, favors surgery, as it does in this comparison. Reintervention after ASA has a whopping hazard ratio of 33, with an upper confidence limit of 251. However, $82 \%$ of patients avoided another procedure after ASA (21 reinterventions in 115 patients available for follow-up). The hazard ratio is large, however, because there were so few reinterventions in the myectomy cohort. In this series the vast majority of patients undergoing ASA avoided a reintervention.

If the patient were to ask "Is there a difference in survival?" or "How well I will feel with these two procedures?" the answer is that it depends. If the patient fits the

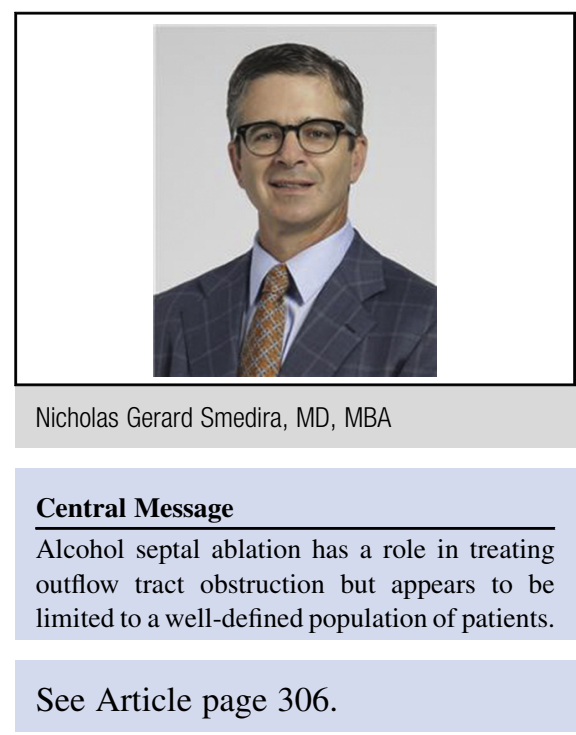

profile of the matched pairs compared in this analysis, which is the key, survival, resting gradients, and late functional class are the same. It is noteworthy that in the unmatched groups, the lowest quartile of age in the ASA group overlapped the highest quartile in the myectomy group, and after matching the median age in the myectomy cohort increased by more than a decade from 54 to 65 years. This suggests that the matched cohorts studied were older populations, and the results cannot be generalized beyond these patients.

Where the data are incomplete and long-term implications unknown is the area of impact of residual gradients on cardiovascular outcomes. It is very likely that provoked gradients, if measured, would be substantially higher in the ASA cohort. Do residual gradients matter? One would think so, especially for younger, more active patients.

I have not mentioned hospital costs, length of stay, patient discomfort, and earlier return to work and lifestyle activities advantages for ASA, or the challenges of reintervention and higher pacemaker rates if a myectomy is required after ASA. I would offer patients 65 years of age or older all the information from a series like this to help them make a well-informed decision in choosing the procedure most appropriate for them. For all other patients with outflow tract obstruction, especially younger patients, patients with very a hypertrophied septum, diffuse chamber hypertrophy, high resting gradients, or minimal hypertrophy, I and my colleagues in treating hypertrophic obstructive cardiomyopathy favor surgical intervention and reserve alcohol for its other medicinal benefits. 


\section{References}

1. Mayo Clinic Staff. Alcohol: if you drink, keep it moderate. Available at: https:// www.mayoclinic.org/healthy-lifestyle/nutrition-and-healthy-eating/in-depth/ alcohol/art-20044551. Accessed October 9, 2018.
2. Nguyen A, Schaff HV, Hang D, Nishimura RA, Geske JB, Dearani JA, et al. Sur gical myectomy versus alcohol septal ablation for obstructive hypertrophic cardiomyopathy: a propensity score-matched cohort. J Thorac Cardiovasc Surg. 2019; 157:306-15.e3. 